\title{
ILUMINANDO AS VIVÊNCIAS DE INDIVÍDUOS EM SOFRIMENTO PSÍQUICO DE UM CAPS EM FLORIANÓPOLIS ${ }^{1}$ ILLUMINATING THE EXPERIENCES OF INDIVIDUALS IN PSYCHIC SUFFERING OF A CAPS IN FLORIANÓPOLIS ILUMINANDO LAS VIVENCIAS DE INDIVIDUOS EN SUFRIMIENTO PSÍQUICO DE UN CAPS EN FLORIANÓPOLIS
}

\author{
Dorotéa Loes Ribas², Miriam Süsskind Borenstein, Maria Itayra Coelho de Souza Padilhat
}

\begin{abstract}
${ }^{1}$ Este estudo é resultado da dissertação "O portador de transtorno mental: vivenciando suas experiências do cotidiano buscando ser mais", defendida no Programa de Pós-Graduação em Enfermagem (PEN) da Universidade Federal de Santa Catarina (UFSC), em 2004.

${ }^{2}$ Mestre em Assistência de Enfermagem. Enfermeira do Centro de Atenção Psicossocial (CAPS), Florianópolis-SC. Membro efetivo do Grupo de Estudos de História do Conhecimento da Enfermagem (GEHCE).

${ }^{3}$ Doutora em Filosofia da Enfermagem. Professora Adjunto do Departamento de Enfermagem da UFSC. Coordenadora do GEHCE, Pesquisadora do Conselho Nacional de Desenvolvimento Científico e Tecnológico (CNPq).

${ }^{4}$ Doutora em Enfermagem. Professora Adjunto do Departamento de Enfermagem da UFSC. Vice-Coordenadora do GEHCE. Pesquisadora do CNPq.
\end{abstract}

PALAVRAS-CHAVE: Saúde mental. Enfermagem psiquiátrica. Psiquiatria.

RESUMO: Trata-se de uma pesquisa qualitativa cujo objetivo foi refletir com o indivíduo em sofrimento psíquico, suas experiências vividas no cotidiano, identificando os significados destas experiências. $O$ estudo foi realizado com dois clientes de um Centro de Atenção Psicossocial (CAPS II), em Florianópolis. A coleta dos dados ocorreu a partir da implementação do processo de cuidado, segundo a Teoria de Rosemarie Rizzo Parse. $\mathrm{Na}$ análise dos dados foram identificados os seguintes significados: convivendo com as lembranças da infância; a co-constituição da doença psiquiátrica; o trabalho permeando o processo saúdedoença; transcendendo em saúde, cidadania e qualidade de vida, iluminados pela Reforma da Assistência Psiquiátrica. Assim, a teoria "Tornar-se Humano", com seus conceitos, princípios e pressupostos permitiu ao indivíduo em sofrimento psíquico vislumbrar de uma nova maneira de viver, afinada com a proposta da Reforma Psiquiátrica Brasileira.

KEYWORDS: Mental health. Psychiatric nursing. Psychiatry.

\begin{abstract}
This article presents qualitative research which sought to reflect with individuals who experience psychic suffering about their daily experiences, identifying the meanings of such experiences. The study was carried out with two patients of a Psychosocial Care Center (CAPS II), in Florianópolis, Santa Catarina, Brazil. The data was collected through the implementation of Rosemarie Rizzo Parse's Care Process Theory. Through the data analysis, the following meanings were identified: coexisting with infancy memories; co-constitution of the psychiatric illness; the work permeating the healthillness process; transcending in health, citizenship, and quality of life, illuminated by the Psychiatric Care Reform. Thus, the "Becoming Human" theory, with its concepts and principles, allowed the individuals in psychic suffering to glimpse a new way of living, sharpened with the proposal of the Brazilian Psychiatric Reform.
\end{abstract}

RESUMEN: En el presente estudio se realizó una investigación cualitativa cuyo objetivo fue reflexionar, con el individuo en sufrimiento psíquico, sus experiencias vividas en el cotidiano, identificando los significados de estas experiencias. El estudio fue realizado con dos clientes de un Centro de Atención Psicosocial (CAPS II), en la ciudad de Florianópolis. La recolección de los datos fue hecha a partir de la implantación del proceso de cuidado, según la Teoría de Rosemarie Rizzo Parse. En el análisis de los datos fueron identificados los siguientes significados: conviviendo con los recuerdos de la infancia; la co-constitución de la enfermedad psiquiátrica; el trabajo penetrando el proceso salud-enfermedad; transcendiendo en salud, ciudadanía y calidad de vida; iluminados por la Reforma de la Asistencia Psiquiátrica. De esa forma, la teoría "Volverse Humano", con sus conceptos, principios y presupuestos le permitió al individuo en sufrimiento psíquico vislumbrar una nueva manera de vivir, relacionada con la propuesta de la Reforma Psiquiátrica Brasileña.

PALABRAS CLAVE: Salud mental. Enfermería psiquiátrica. Psiquiatría.
Artigo original: Pesquisa Recebido em: 15 de agosto de 2006. Aprovação final: 20 de dezembro de 2006.
R. Camilo Silveira de Souza, 416

88.090-200 - Capoeiras, Florianópolis, SC.

Email: dorotearibas@hotmail.com 


\section{INTRODUÇÃO}

Nas duas últimas décadas, visualizamos no âmbito da Reforma Psiquiátrica Brasileira, avanços expressivos que contribuíram significativamente na melhoria da assistência psiquiátrica. A enfermagem no bojo dessas transformações vem se preocupando em prestar uma assistência mais adequada, resgatando a cidadania e buscando propiciar melhor qualidade de vida ao indivíduo em sofrimento psíquico.

A criação de Núcleos/Centros de Atendimento de Atenção Psicossocial (NAPS/CAPS) através da Portaria No 224, de 29 de janeiro de 1992, tem contribuído significativamente para a melhoria da assistência aos indivíduos em sofrimento psíquico. ${ }^{1}$ Estes NAPS/CAPS foram instituídos como unidades de saúde locais/regionalizadas, e oferecem atendimentos de cuidados intermediários entre o regime ambulatorial e a internação hospitalar. Devem ser a porta de entrada da rede de serviços para ações relativas à saúde mental. Devem atender pacientes referenciados por outros serviços de saúde, dos serviços de urgência psiquiátricos ou ainda egressos de internação hospitalar. Devem estar integrados a uma rede descentralizada e hierarquizada de cuidados em saúde mental, funcionar em horário comercial, assistidos por uma equipe multiprofissional, constituídos prioritariamente por médico psiquiatra, psicóloga, enfermeira e assistente social..$^{2}$

Os NAPS/CAPS passaram a ser uma alternativa bastante positiva no tratamento dos doentes psiquiátricos crônicos, que até então, eram atendidos no âmbito hospitalar ou no domićlío sem o acompanhamento adequado.

Em Santa Catarina, antes mesmo da criação do CAPS/NAPS pelo governo federal, já vinha ocorrendo uma mudança de mentalidade em termos técnicos e políticos, pois, na década de 70, o governo estadual que pretendia construir novos hospícios, resolveu desistir, deixando de inaugurar o Hospital Psiquiátrico de Chapecó. Passou a implementar um programa de diminuição gradativa de leitos no macro Hospital Colônia Sant'Ana (atual Instituto de Psiquiatria de Santa Catarina - IPQ), dotando este hospital, de um número maior de recursos humanos e materiais. ${ }^{3}$

Neste contexto de mudanças, foi criado em 1989, o CAPS de Florianópolis, para realizar a assistência à clientes adultos que apresentassem sofrimento psíquico e outros problemas relacionados. Tratava-se do primeiro recurso não manicomial da rede pública estatal.
Desde o final da década de 80 este CAPS tem possibilitado o atendimento a uma crescente demanda de indivíduos em sofrimento psíquico e tem tido uma atuação expressiva, contribuindo para que muitos portadores deixassem de internar frequientemente em hospitais psiquiátricos, e se mantivessem em tratamento ambulatorial, podendo conviver com seus familiares e amigos. ${ }^{3}$

Como enfermeiras atuando nesse serviço desde o início dos anos 90, embora procurando assistir aos clientes de forma integral, sentíamos que necessitava nos instrumentalizar melhor, para podermos assistir a esta clientela, utilizando entre outros, de um referencial teórico que pudesse subsidiar a prática profissional. Face à essa questão, associados a outros interesses pessoais e acadêmicos, resolvemos realizar o Curso de Mestrado em Enfermagem na Universidade Federal de Santa Catarina (UFSC) e assim, consubstanciar a prática, possibilitando prestar uma assistência mais sistematizada, consistente teoricamente e humana aos indivíduos em sofrimento psíquico.

Com base na proposta da Reforma Psiquiátrica Brasileira e a partir do conhecimento mais aprofundado da teoria "Tornar-se Humano", ${ }^{4}$ percebemos que esses referenciais poderiam servir de base teórica para a realização deste estudo. Segundo esta teoria, a enfermeira esclarece os significados que emergem das situações cotidianas dos clientes, compartilhando com estes, seus pensamentos e sentimentos. ${ }^{4} \mathrm{O}$ ser humano a partir dos significados de suas experiências vividas, é capaz de co-criar novas possibilidades de vida e saúde, podendo transcender à este significado, buscando "ir além".

Esse estudo portanto, tem como objetivo refletir com o indivíduo em sofrimento psíquico, suas experiências vividas no cotidiano, identificando os significados e visando atingir uma melhor qualidade de vida.

\section{METODOLOGIA}

Trata-se de uma pesquisa qualitativa do tipo convergente assistencial, na qual foi utilizada a abordagem metodológica da teoria "Tornar-se humano", ${ }^{4}$ que traz em seu bojo, características de valorização da pessoa como responsável pela sua saúde, e por si próprio, podendo transcender, mudando seu comportamento e atingindo uma melhor qualidade de vida.

Participaram do estudo, dois usuários do CAPS de Florianópolis, que foram selecionados 
a partir dos seguintes critérios estabelecidos: ser indivíduo em sofrimento psíquico; estar orientado no tempo e espaço; não apresentar delírios nem alucinações, possuir condições de vir ao CAPS e principalmente ter interesse de participar dos encontros previamente agendados.

A coleta de dados ocorreu em oito encontros individuais, com aproximadamente duas horas, e seguiu a proposta de cuidado segundo Parse, ${ }^{4} \mathrm{em}$ suas três dimensões, ou seja: 1) buscou-se iluminar os significados das vivências dos participantes; 2) sincronizar os ritmos que apareceram no processo da cadência inter-humana e finalmente 3 ) mobilizar para a transcendência, que se deu pelo processo de ir além dos significados das vivências para o processo de mudanças nos padrões de comportamento. Os dados foram coletados no período entre setembro de 2002 a junho de 2003, com a finalidade de observar a terceira dimensão da prática metodológica, ou seja, da transcendência. Embora a idéia inicial fosse realizar a coleta de dados no CAPS, por motivo de doença de um dos participantes, alguns encontros foram realizados no domicílio deste.

O projeto foi encaminhado para a Diretoria Geral da Policlínica de Referência Regional do Estado de Santa Catarina, que autorizou a realização da pesquisa envolvendo os usuários do CAPS. Além disso, os clientes foram orientados quanto ao Termo de Consentimento Livre e Esclarecido e o direito ou não de participar da pesquisa, respeitando o exigido pela Resolução No 196/96, do Conselho Nacional de Saúde. ${ }^{5}$ Somente após as devidas autorizações, os dados passaram a ser coletados.

Para análise dos dados, foram utilizadas as duas etapas metodológicas propostas pela Teoria de Parse: a extração de síntese e a interpretação heurística. $\mathrm{Na}$ extração de síntese, buscou-se resgatar a essência dos diálogos na linguagem própria dos participantes. A interpretação heurística ocorreu através da interpretação dos significados que emergiram, fazendo uma conexão entre estes, com a estrutura da teoria, resultando em um novo conhecimento e compreensão da experiência vivenciada. ${ }^{4}$

A partir da análise dos dados emergiram os seguintes significados: convivendo com as lembranças da infância; a co-constituição da doença psiquiátrica; o trabalho permeando o processo saúde-doença; transcendendo em saúde, cidadania e qualidade de vida, iluminados pela Reforma da Assistência Psiquiátrica.

\section{APRESENTACÃO DOS RESULTADOS}

\section{Convivendo com as lembranças da infância}

A infância caracteriza-se pelo período que compreende desde o nascimento até idade aproximada de doze anos. ${ }^{6}$ Neste período, ocorrem as primeiras trocas entre as crianças e o meio onde vivem, a criação de vínculos, as socializações, as brincadeiras e a aprendizagem.

$\mathrm{Na}$ infância, o universo da criança é constituído basicamente pelos pais, sendo que a relação com a mãe é a que ocorre com maior intensidade, principalmente porque é esta, quem supre as necessidades de alimento, higiene, conforto, segurança, passando a ser a maior fonte de prazer para a criança. ${ }^{6}$

A atenção que as mães costumam proporcionar aos seus filhos, suprindo suas necessidades, oferece condições suficientes e necessárias para que se estabeleça entre estes, um sentimento de unidade, mãe e filho, e ocorra harmonia, equilíbrio e segurança.

Quando se abordou, nesse estudo, como foi a infância dos participantes, os mesmos relataram ter sido muito conflituosa. Um deles, referiu: eu sinto uma grande tristeza ao relembrar minha infância, porque minha mãe, quis me dar inúmeras vezes para outras pessoas. Atéperdi a conta de quantas vezes ela quis me dar. Inclusive, en fugi todas as vezes da casa dessas pessoas e voltava sempre para minha (Alemão).

Enquanto que Alemão, relembra com tristeza, o sentimento de desapego e abandono provocado pela sua mãe, o outro participante, denominado de Eduardo, refere, que era o pai quem costumava cuidá-lo, pois sua mãe sofria de depressão. $\mathrm{O}$ pai caracterizava-se como uma pessoa violenta e opressora, que causava sérios conflitos e provocava insegurança. Como pode ser visualizado na fala: meu pai me surrava, de sair sangue. Tinha vezes que não conseguia vender as frutas e verdura, que ele me dava para eu vender e quando voltava para casa, com pouco dinheiro, apanhava sem parar. Sem dó nem piedade. Era um tormento (Eduardo).

Observa-se nesses dois relatos, um profundo sentimento de tristeza na relação estabelecida com os pais. Estes deveriam proporcionar o amor, o afeto, a atenção, a segurança física e emocional, tão necessários para um desenvolvimento saudável da criança. No entanto, ao contrário, agiam deliberadamente como pessoas insensíveis, irracionais, e até mesmo maldosas, incapazes de compreender o seu real papel no desenvolvimento dos seus filhos.

Outro aspecto ressaltado pelos participantes, estava relacionado com o processo de socialização. 
Neste estudo, os participantes referiram que esse processo não ocorreu facilmente, conforme pode ser visualizado: meu pai proibia que en estabelecesse relaçôes de amizade com os colegas de escola e vizinhos. Não permitia que trouxesse meus "coleguinhas" para brincar em casa. Nunca tive muitos amigos, vivia muito sozinho (Alemão).

Isso dificultou as primeiras experiências e a possibilidade de adquirir o autocontrole. Este tipo de interação serve para constituir as primeiras relações com os outros. Serve para construir a identidade do indivíduo, melhorar sua auto-estima e auto-imagem. Analisando estas vivências, verifica-se uma incoerência com o que é apregoado pelo Relatório da UNICEF, que refere que viver uma "boa infância", inclui o amor, o afeto, a socialização e outras necessidades. ${ }^{8}$ A partir disso, temos a certeza de poder colher bons frutos e contribuir para a formação de um indivíduo saudável e equilibrado. Em contrapartida, quando as necessidades humanas básicas dos indivíduos não são satisfeitas, podem resultar em desequilíbrio e até mesmo na doença. ${ }^{9}$

\section{A co-constituição da doença psiquiátrica}

Um dos significados que surgiu na vivência com os clientes deste estudo, está relacionado com a experiência da doença, ou seja como ela se desencadeou. Os dois participantes tiveram experiências diferenciadas. Alemão apresentou delírios, insônia, medo, isolamento e manifestou comportamento bizarro. Eduardo, por sua vez, passou a apresentar manifestações de depressão com risco de suicídio, o que contribuiu ainda mais, para o agravamento do seu processo saúde-doença.

Eu não dormia, não tinha sono. Tanto é que no meu serviço, trabalhava outro colega comigo. O men colega dormia a noite toda, enquanto que eu não conseguia pegar no sono. Eu me isolava em casa, ficava nervoso, tinha conflitos com meus familiares. Depois fui vendo e ouvindo "coisas". Isto me deixava com medo. Ai veio esse negócio de "espirito". Comecei a não comer. Ficar deitado o dia todo. E botava uma porção de roupa, tinha muito frio, ficava todo encolbido no canto do quarto (Alemão).

Inicialmente Alemão sentiu esses problemas em sua residência, depois passou apresentá-los também no seu emprego, e ficou mais visível ao agredir um colega. Eduardo ao contrário, passou a apresentar manifestações de tristeza, desânimo, sentimentos de inferioridade e vontade de morrer. Isso ocorria, tanto em sua residência, como em seu local de trabalho. Foi uma experiência horrivel. Sentia-me pouco valorizado e querido pelas pessoas ao meu redor. Não me cuidava. Fiquei desatinado, planejei várias formas para dar um fim em minha vida (Eduardo).

Geralmente a depressão é caracterizada pela lentificação dos processos psíquicos e do humor. Ocorre em geral uma redução de energia, uma incapacidade parcial ou total de sentir alegria e/ou prazer. A depressão provoca o desinteresse pelas coisas em geral, até mesmo, por aquelas, que a pessoa sentia prazer. Provoca a apatia ou agitação psicomotora. Muitas vezes, a pessoa apresenta dificuldade de concentração, tem pensamentos negativos acerca de si próprio e dos outros, e pode ter uma imagem distorcida da realidade. ${ }^{10}$ Quando as situações se tornam angustiantes e causam intenso sofrimento, são comuns, as tentativas de suicídio, que podem ter um desfecho trágico.

Os momentos em que os clientes tinham maior exacerbação da doença eram permeados pelo sentimento de sofrimento. Um sofrer psíquico, cujas características não se apresentavam de forma clara para o entendimento comum, do grupo social no qual estavam inseridos. A própria família sofre muito com as alterações que passam a ocorrer no ambiente familiar. A sociedade também contribui para a exclusão do indivíduo em sofrimento psíquico e até mesmo para com sua família, pois não compreende a situação vivenciada por estes.

Embora com todas as dificuldades manifestadas pelos participantes, na fase mais aguda da doença, ou seja, quando os sintomas se exacerbaram, estes puderam contar com ajuda da equipe de saúde do CAPS. Conseguiam assim, se reerguer, e passar a viver um pouco melhor com seus amigos e familiares.

\section{O trabalho permeando o processo saúde-doença}

O trabalho permite que os indivíduos se tornem produtivos, e adquiram uma situação econômica estável, para que possam viver com conforto e segurança. Além disso, que estabeleçam relações com outros seres humanos. Muitas vezes, estas relações podem evoluir para uma amizade duradoura. Para o indivíduo em sofrimento psíquico, a exemplo da pessoa considerada "saudável", o trabalho permite a construção de relações nos diferentes ambientes que estes se inserem, e é fundamental para o seu equilíbrio e harmonia, diminuindo o seu isolamento. ${ }^{11}$

Entretanto nem sempre esse ambiente se constitui de forma saudável, causando alterações no estado físico, psíquico e social do indivíduo, desencadeando a doença. Há autores que referem 
que o exercício de determinadas atividades profissionais, em condições insalubres, possibilitam o aparecimento de doenças. ${ }^{12}$

Neste estudo foi possível perceber que o processo de adoecer foi se constituindo no cotidiano do trabalho, a partir da convivência diária com o sofrimento humano. Para Eduardo, assistir aos pacientes internados com doenças graves, não era uma atividade fácil, muito menos tranqüila. O que me levou a sair da enfermagem foi a convivência com o sofrimento dos pacientes. Não conseguia mais conviver com tanto sofrimento bumano no hospital. Isto mexia com meus sentimentos. Não conseguia separar os sentimentos profissionais dos pessoais (Eduardo).

Quanto a Alemão, este relata que sua experiência no trabalho, se caracterizou em momentos angustiantes: eu tinha horário para dormir no meu trabalho, pois eu trabalhava no periodo noturno, mas eu não dormia no meu horário de folga, eu não tinha sono. Tanto é que no meu serviço, trabalhava outro colega comigo, então ele dormia no meu lugar. Eu comecei a ver coisas, vultos, fantasmas, ficar cada vez mais com medo. Fui me apavorando. Entrei em desespero e aí adoeci (Alemão).

Os estímulos negativos do ambiente de trabalho, ocasionam algumas vezes, o aparecimento de conflitos internos. Em muitas ocasiões, o indivíduo não consegue separar o profissional do pessoal. Passa a ficar confuso, especialmente quando não possui uma boa estrutura psicológica que lhe dê uma certa sustentação. No caso de Alemão, esse processo vinha se arrastando, inicialmente com uma infância difícil e sofrida, com falta de apoio, afeto e segurança familiar. E posteriormente, com um casamento com dificuldades de relacionamento com a esposa. Analisando as questões referente ao trabalho e o processo saúde-doença, um questionamento emerge: será que podemos afirmar que o local de trabalho contribuiu efetivamente para o adoecimento dos participantes deste estudo? Ou estes, já apresentavam uma certa predisposição para que ocorresse a doença?

Contudo, as questões levantadas relacionadas ao trabalho são paradoxais, pois como o trabalho pode ter desencadeado o adoecer, pode também gerar possibilidades de saúde. Hoje, ambos os participantes desse estudo, buscam trabalhar dentro de suas condições psíquicas e físicas para sobreviver, melhorar sua auto-estima e seguir vivendo com mais qualidade de vida. Possuir um emprego ou um trabalho, aumenta substancialmente a satisfação consigo próprio, a auto-estima, a auto-imagem dos indivíduos, criando oportunidades de socialização e comunicação. ${ }^{11}$ A confirmação desse processo, pode ser visualizado através da fala de Eduardo, que ao mudar de atividades de trabalho, refere: hoje estou muito bem, sinto-me útil. Atuo bá seis meses neste setor da vigilância sanitária. Eles gostam muito de mim e do men trabalho (Eduardo).

O trabalho pode constituir-se para alguns indivíduos em sofrimento psíquico, em uma experiência muito positiva e com significados saudáveis. Pode restabelecer a sua saúde, possibilitando que o indivíduo se torne um sujeito ativo, participante, desenvolvendo uma melhor qualidade de vida, visando sua reabilitação psicossocial.

\section{Transcendendo em saúde, cidadania e qualidade de vida, iluminados pela Reforma da Assistência Psiquiátrica}

A terceira dimensão da prática metodológica de "Tornar-se humano", acontece através do processo de "ir além" do significado daquele momento para "vir a ser". Ou seja, o indivíduo ultrapassa suas dificuldades, muda seus comportamentos e atitudes, superando aquelas situações que não conseguia resolver. "Os sonhos se tornam realidade, através de mudança nos padrões vividos até então, tudo o que era, passa a ser". $4: 322$

O processo de interação entre o indivíduo em sofrimento psíquico e a enfermeira, nessa terceira dimensão deve resultar na melhora do estado de saúde do primeiro. É um processo de mudança do significado emergido, dos relacionamentos vividos com os outros e com o universo. A saúde é o resultado da experiência vivida e a qualidade de vida se revela na perspectiva do próprio indivíduo. ${ }^{4}$

Em suas falas os participantes do estudo têm procurado experienciar o processo de transformação no seu cotidiano, no seu modo de ser, fazer e de se relacionar. É um processo difícil, vivido com angústia, sofrimento, limitações e recaídas. Mas que, dentro das possibilidades de cada um, tem conseguido evoluir, no propósito de Ser Mais. Eu tenho feito pipas é só colocaro papel, barbante e vareta e já faço a pipa. Esta atividade me ajuda a sair da depressão e afasta os pensamentos ruins, e a obsessão em dar fim em minha vida. Eu tenho medo de voltar a sentir o que sentia antes. Depois que eu passei a construir as pipas, en eston mais felir, principalmente porque enche o meu tempo e faço as pessoas mais felizes. Isso é muito bom (Eduardo).

Nessa fala, observa-se um esforço que Eduardo tem feito para superar os seus problemas. Relata que com seus dons artísticos tem possibilitado melhorar seu quadro psiquiátrico, confeccionando objetos de arte e utilidade que podem produzir recreação e la- 
zer. Esses objetos alegram as crianças e até mesmo, os adultos. Quanto ao participante Alemão, este refere que a aposentadoria precoce provocou sentimentos de incapacidade e desvalorização. Entretanto, ele não desistiu da luta e buscou novas possibilidades de trabalho: en vou trabalhar carregando saco de ração. Vou limpar, cuidar dos passarinhos, para vender. Também posso negociar cachorro que é uma coisa que eu gosto (Alemão).

Podemos visualizar que mesmo o Alemão tendo vivenciado uma aposentadoria precoce (35 anos), conseguiu superar, buscando realização em outras atividades, que proporcionam satisfação, dentro de suas limitações. Ultrapassar esta barreira para o indivíduo em sofrimento psíquico, significa conquistar seu espaço, buscando ser mais, através da melhora da qualidade de vida.

Com relação a Eduardo, este também tem feito um esforço enorme para superar os seus problemas. Buscando a co-constituição de um processo mais saudável. Vivendo de forma mais positiva, procurando relacionar-se melhor com as pessoas no seu ambiente, e estabelecendo metas e atividades compatíveis e exeqüíveis com sua condição de saúde e vida. Pretendo terminar minha casa. Plantar árvores frutiferas porque tem muito espaço ao redor da casa e assim, viver bem melhor (Eduardo).

No que se refere a doença propriamente dita, Alemão demonstra interesse em saber mais sobre a mesma, sobre o seu tratamento e as perspectivas futuras. Conforme assinala a seguir: antes minha familia e a de minha esposa me rejeitavam, ai comecei a trazer folhetos do CAPS que tinham explicações sobre a doença mental. Acho que isto fez. com que mudasse a nossa relação familiar (Alemão).

Eduardo não demonstrou uma preocupação excessiva em conhecer os aspectos relativos a doença mental, pois como foi auxiliar de enfermagem (conversamos inúmeras vezes sobre sua profissão e seu conhecimento acerca das doenças de um modo geral), consegue visualizar melhor seus problemas e encontrar soluções para os mesmos. Inclusive, buscando soluções relativamente simples que tem dado bom resultado. $\mathrm{Na}$ fala a seguir, ele descreve como passou a equacionar esse problema: en escrevo tudo, faço bilhetes para mim mesmo. Vou anotando tudo o que as pessoas pedem. Assim não fico preocupado, quando bá cobranças, pois está tudo escrito e não há como esquecer (Eduardo).

A aceitação da doença é o primeiro passo, e é fundamental para o sucesso do tratamento. ${ }^{13}$ No contexto destas experiências, pelas quais ambos vêm passando, ressaltamos a importância do CAPS como a mola propulsora para contribuir na assistência psiquiátrica. Isto só foi possível a partir da Reforma Psiquiátrica instituída no país, pois até a década de 90 , assistência psiquiátrica era basicamente hospitalocêntrica. Os indivíduos não tinham a quem recorrer, e na maioria das vezes a solução era a internação. No CAPS, o indivíduo tem a oportunidade de passar o dia e contar com o apoio da equipe multidisciplinar. Muitas vezes em conversas e consultas com os profissionais, os doentes conseguem resolver muitos dos seus problemas e pelo menos, minimizá-los.

\section{CONSIDERAÇÕES FINAIS}

Para o indivíduo em sofrimento psíquico que convivia com crises, seguidas de internação hospitalar, o CAPS vem possibilitando a realização do tratamento em nível ambulatorial, com ajuda dos profissionais, em especial das enfermeiras. São estas profissionais, quem na maioria das vezes, tem conseguido dar um suporte aos indivíduos em sofrimento psíquico e suas famílias. Dessa forma, este consegue enfrentar as crises em seu ambiente familiar, evitando a internação e conseqüentemente diminuindo a cronicidade.

Sabemos que há casos em que a crise não consegue ser debelada em nível ambulatorial. Mas o empenho profissional é no sentido de que cada vez mais o indivíduo em sofrimento psíquico possa sonhar com essas e outras possibilidades. Encontrar formas de tratamento que possibilitem "ser mais" na sua condição de ser e viver.

Sendo assim, estes serviços não significaram apenas alternativas para a não-internação hospitalar mas, aos poucos, começaram a ser espaços de acolhimento e assistência para o doente mental e sua família. ${ }^{3,14-15}$

Acreditamos que a reforma da assistência psiquiátrica brasileira gradativamente venha transcendendo os muros do manicômio, respeitando o indivíduo na sua singularidade, no seu modo de ser, tornando-se sujeito ativo do seu próprio processo saúde-doença. Desta forma, podemos observar que os participantes estão co-construindo dentro de suas possibilidades, nesta experiência "terapêutica", um "mundo" fora dos muros do manicômio.

Este estudo fundamentado no referencial teórico de Rosemarie Rizzo Parse, realizado num CAPS em Florianópolis e na residência de um dos sujeitos, apresenta algumas facetas das experiências vivenciadas por cada um dos participantes, reve- 
lando seu modo de ser, viver na subjetividade e se relacionar, trazendo a singularidade de cada um.

Para os profissionais envolvidos nesse processo, foi uma experiência ímpar. A trajetória foi permeada por algumas dificuldades, tais como: o reduzido tempo para os encontros e as distâncias percorridas; os assuntos que emergiram, e as dificuldades para resolver imediatamente as questões apresentadas e finalmente a falta de experiência com o referencial adotado. Embora com alguns contratempos, o trabalho chegou ao seu final, de maneira surpreendente, com o transcender dos participantes e a emancipação das pesquisadoras. É importante ressaltar que a emancipação do trabalhador de saúde mental, oportuniza que este ofereça um cuidado mais humanizado ao indivíduo em sofrimento psíquico, gerando condições propícias para que este também possa se emancipar. ${ }^{15}$

Consideramos que este trabalho, baseado na teoria “Tornar-se Humano", de Parse, possibilitou olhar o indivíduo em sofrimento psíquico, de maneira mais respeitosa e compreensiva, respeitando-o como cidadão, capaz de viver com dignidade e amor como qualquer outro ser humano. Contribuiu para formação de um corpo de conhecimentos científicos de enfermagem e em um novo modo de assistir a indivíduos em sofrimento psíquico.

\section{REFERÊNCIAS}

1 Brasil. Portaria No 224, de 29 de janeiro de 1992. Dispõe sobre normas diretrizes para os atendimentos hospitalares e extra-hospitalares. Diário Oficial da República Federativa do Brasil, 30 Jan. 1992. Seção 1, p.1168-70.

2 Ministério da Saúde (BR), Coordenação de Saúde Mental. Relatório final. In: Anais da 2a Conferência Nacional de Saúde Mental; 1992 Dez 1-4; Brasília, Brasil. Brasília (DF): O Ministério; 1994.
3 Ribas DL. Borenstein MS. CAPS - Florianópolis: uma experiência de grupo com clientes psicóticos fora dos muros do manicômio, durante dez anos. Rev. Bras. Enferm. 1999 Abr-Jun. 52 (2): 179-88.

4 Parse RR. Illuminations: the human becoming theory in practice and research. New York (USA): National League for Nursing; 1995.

5 Ministério da Saúde (BR), Conselho Nacional de Saúde, Comitê Nacional de Ética em Pesquisa em Seres Humanos. Resolução No 196 de 10 de outubro de 1996: diretrizes e normas regulamentadoras de pesquisa envolvendo pesquisa seres humanos. Brasília (BR): O Conselho; 1996.

6 Dally P. Harrington H. Psicologia e psiquiatria na enfermagem. São Paulo (SP): EPU/EDUSP; 1978.

7 Winnicott DW. A família e o desenvolvimento individual. São Paulo (SP): Martins; 1993.

8 Fundo das Nações Unidas para a Infância. Relatório da sessão especial da assembléia Geral das Nações Unidas sobre a criança. Nova York (USA): UNICEF; 2002 [acesso em 2004 Abr 30]. Disponível em: http// www.unicef.org.br/

9 Horta W. A. Processo de enfermagem. São Paulo (SP): EPU/ EDUSP; 1979.

10 Moreno RA, Moreno DH. Transtornos do humor. In: Louzã Neto MR. Psiquiatria básica. Porto Alegre (RS): Artes Médicas; 1995. p.136-66.

11 Bertolote JM. Reabilitação psicossocial: a favor de um consenso. Geneva (Suíça): WHO; 1997.

12 Tsu T. A internação psiquiátrica e o drama das famílias. São Paulo (SP): EDUSP; 1993.

13 Louzã M R, Shirakawa I. O Enfoque médico atual. In: Louzã Neto M R., Shirakawa A I, Barros L. Esquizofrenia: dois enfoques complementares. São Paulo (SP): Lemos Editorial; 2000. p.13-44.

14 Scatena MCM. Saindo do hospital psiquiátrico: análise da inserção dos pacientes nos lares protegidos [tese livredocência]. Ribeirão Preto (SP): USP/EERP; 2000.

15 Prandoni RFS, Padilha MICS. A reforma psiquiátrica no Brasil: eu preciso destas palavras. Texto Contexto Enferm. 2004 Out-Dez; 13 (4): 633-40. 